\title{
Evaluation of biomechanical indices in elite fencing athletes in the criteria of ankle injury after fleche landing
}

\author{
Hokmollahi Fatemeh* \\ Head Coach of Tehran Fencing Association, I.R.I Fencing Federation, Tehran, Iran
}

\section{A R T I C LE INFO}

\section{Article history:}

Received 5 December 2016

Received in revised form

8 February 2017

Accepted 15 February 2017

\section{Keywords:}

Biomechanical indicators

Adolescent and young fencing athletes

Fleche technique

Ankle

\begin{abstract}
A B S T R A C T
The present study aims to compare the evaluation of biomechanical indices in elite and non-elite fencing athletes in the criteria of ankle injury when landing after performing the fleche technique. In this study, 25 fencing athletes with the age range of $17.25 \pm 3.1$ years, the weight range of $60.54 \pm$ $11.3 \mathrm{~kg}$, and the height range of $175.4 \pm 9.5 \mathrm{~cm}$ were randomly selected. Muscular strength measurement is done using bodybuilding devices through isotonic method and one-repetition maximum formula. A standard questionnaire is used to identify and record potential injury rate, and independent $t$ test and Spearman correlation test are used to analyze the data. Also, Excel 2012 and SPSS 19 software are used. Flexibility, static balance, agility, anteromedial, medial, posteromedial, posterior, and posterolateral directions of star excursion balance test were used as the main indices of elite fencing athletes and muscular endurance, dynamic balance, medial, posterolateral, and posterior directions of star excursion balance test were the main biomechanical indices of non-elite fencing athletes. In the comparison of the main indices, there was a significant difference between muscular endurance, agility, static balance, and dynamic balance. The results of data analysis showed that there is a significant relationship between the imbalance of agonist muscle strength in ankle, knee and thigh joints and prevalence of ankle muscle injuries $(\mathrm{P}<.05)$. There is also a significant relationship between the harmony of the antagonist muscles' strength (per joint) and prevalence of ankle muscle injury $(\mathrm{P}<.05)$. In total, according to the results, it can be concluded that imbalance of muscular strength in agonist and antagonist muscles in ankle, knee and hip joints is one of the important predictive risk factors in the incidence of muscle injury in young athletes. Experts should pay due attention to balancing muscular power before the tournaments so as to prevent muscle injury in the abovementioned muscles.
\end{abstract}

(C) 2017 The Authors. Published by IASE. This is an open access article under the CC BY-NC-ND license (http://creativecommons.org/licenses/by-nc-nd/4.0/)

\section{Introduction}

Depending on the type of weapons used, fencing is divided to three types of Foil, Epee, and Sabre. In each weapon, the hitting rules and scoring are different (Rangarajan, 1999). In epee and foil, hits are with the point (tip of the sword), while in the Sabre, in addition to the point, hits are on the blade side. Valid foil targets are chest and back of the fencers, sabre target is the entire body above waist, and the epee target is the entire body (Russell, 1996).

\footnotetext{
* Corresponding Author

Email Address: Hokmollahi.f@gmail.com

https://doi.org/10.21833/ijaas.2017.02.020

2313-626X/C) 2017 The Authors. Published by IASE.

This is an open access article under the CC BY-NC-ND license

(http://creativecommons.org/licenses/by-nc-nd/4.0/)
}

Researches have shown that success in many sports largely depends on athlete's foot power and muscle strength (Aquilino et al., 2012). Abdollah et al. (2014) concluded that there isn't any significant difference between physiological variables (aerobic and anaerobic power, speed) and physical features (muscular endurance, muscular strength) in two groups of successful and semi-successful Sabre fencers.

According to past studies, it seems that this field demands different anthropometric and physiological characteristics depending on the type of weapon and valid targets. Aquili et al. (2013) conducted a study entitled as "performance analysis on 27 foil, epee, and sabre male and female fencers" and concluded that there is a significant difference between reaction time and agility in sabre fencers with other two weapons in both male and female groups and 
males have better reaction time and agility levels. The reasons for these changes can be found in the differences in gender and the way of measuring fencers' factors. The results showed that fencers are significantly different in terms of speed (40 yards), muscular power (long jump) and flexibility (thigh).

Since foil fencers should only target torso, neck, and groin, this has caused them have higher speed and force to get more scores. The reason for thigh flexibility in sabre fencers is that sabre fencers must have more flexible body to hit the torso of the other fencer so that get more scores by hitting the target areas as a result of underacting of the opponent. The results showed that foil fencers have higher muscular strength (long jump) and speed (40 yards) than other two weapon fencers. This study is not in line with the study of Gustavo et al. in terms of muscular strength (long jump). Gustavo et al conducted a study to compare fencers' foot performance of 18 elite male fenders in Argentina's national team. The results showed no significant difference between the foot powers of three weapon fencers (Aquilino et al., 2012).

The reason for differences in results is that Gustavo have just performed tests measuring foot power, while other tests have been taken in this study and it may be due to difference in the measurement methods. The results of this study also showed that sabre fencers' flexibility (thigh) is higher than other two weapon fencers, which is not in line with the results of Da Cunha et al. (2008).

Da Cunha et al. (2008) evaluated the flexibility (thigh, torso) of Brazilian fencers. The results showed that there is no significant difference between the three weapon fencers in terms of thigh and torso flexibility. The reason for the difference of results is that Da Cunha et al. (2008) have studied male and female fencers, while the present study just evaluates male fencers.

Exact evaluation of human muscle performance has always been the aim of sport and rehabilitation experts. Strength, power, and maximum range of joint motion are parameters that are often used most to evaluate the performance of human muscle. Sport specialists have been always interested in comparing the effects of various forces and providing programs to search for the exact amount of muscle power. Those who study rehabilitation want to prove the effect of exercise therapy on the recovery of patients with musculoskeletal injuries. Athletic trainers and sports medicine practitioners emphasize the avoidance of the injuries caused by the detection of shortages of power and power relations of mutual and reciprocal muscle groups (Rattray, 2006; Elliott, 1992).

Muscles strength and their weaknesses have a significant effect on the alignment and function of the body. Muscle strength imbalance disrupts the body's alignment and leads to imposition of unusual pressure on the joints and other tissues. Strength exercises' experts consider the importance of exercises for muscles producing symmetric exercises around a joint (e.g. flexors, extensors, adductors, abductors).

Despite these exercises, it seems that a group of muscles tends to be stronger than the other group. These amounts are of importance for sports medicine specialists when there is a significant difference between symmetrical muscles (dominant member - non-dominant member), and between the agonist and antagonist muscles of joints (Rattray, 2006).

Accordingly, it is assumed that high imbalance ratios in symmetrical muscle groups affect the joints and cause injuries in the muscle groups. For this reason, much attention should be paid to these ratios near the hip, knees, and ankle joints in the observations on the screen and rehabilitation of athletes. Most researchers of muscular imbalance and its relationship with sport injuries believe that if a significant difference is observed between dominant and non-dominant organs and also agonist and antagonist muscles of sportsmen, not only these sportsmen experience significant reduction in their sport performance, but also most of these people suffer from sports injuries, especially muscle injuries (Vilas-Boas et al., 2003). Findings of several studies suggest that from among fitness and health indices, strength has been discussed and considered more than other factors in the debate on sport pathology and rehabilitation (Benvenuti et al., 2010; Davlin, 2004). There is a relative consensus view in foreign studies (Knudson, 1993; Elliott, 1992; Vila et al., 2011; Özkol et al., 2013) which suggested that if there is a significant difference of about $5-10 \%$ in the strength of symmetrical muscles (dominant and nondominant organs) and if the relative coordination power of agonist and antagonist muscles on both sides of a joint is less than .60-75 (in knee and sagittal plane), .80-85 (in hip and frontal plane), and .45-65 (in ankle and sagittal plane), the person will eventually experience injuries in the same muscle and joint.

Elliott (1992) evaluated the isokinetic muscle imbalance and incidence of knee injuries on a sample of 170 randomly selected high school fencers and kept track of injured samples and concluded that the rate of various knee injuries reaches the highest level when the difference in the strength of left and right feet is more than $10 \%$.

In other study, Oudejans et al. (2002) reported $122.4 \mathrm{lb}-\mathrm{ft}$ as the strength of extensor muscles in non-injured athletes and $104 \mathrm{lb}$ - $\mathrm{ft}$ as the strength of extensor muscles in injured athletes. Also, the lack of extensors' strength is a key factor in the incidence of injuries in the muscles. Clearly (2001) reported that the strength of plantar flexor and dorsi flexor in speed runners' feet is 76 and $25.1 \mathrm{lb}-\mathrm{ft}$, respectively.

Based on healthy and injured athletes' strength, flexors strength coordination and correlation ratio of flexors strength to knee extensors are $65 \%$ in healthy people and $51 \%$ in injured people. In similar studies, the main problem in the prevention and treatment of muscle injuries is exact evaluation of muscle strength and given that strength changes 
independently, knowing normal mean values of strength of muscles around the knee joint is placed after injuries and time of returning to be active in terms of sport planning and physical therapy. Studying university female athletes has shown that injured subjects are faced with the following issues in their lower limbs:

- Their right knee flexor isokinetic strength is $15 \%$ stronger than their left knee flexor (at a speed rate of 180 degrees per second).

- Coordination rate of knee extensor strength to knee flexors of subjects is less than $75 \%$ (at a speed rate of 180 degrees per second).

Vilas-Boas et al. (2003) investigated factors creating central stability in 433 professional firefighters and said that strength is one of the most important factors in creating central stability. They also stated that muscle weakness is a predictor of sports injuries.

Based on what was said, the aim of this study is comparing the biomechanical indices' evaluation in elite and non-elite fencers in the criteria of injury when landing after performing fleche technique.

\section{Methodology}

According to the topic of the present research, it is a descriptive longitudinal prospective study. Study population includes all young male club athletes from 15 to 19 years old in Tehran city, who were fencers of Tehran Fencing Committee club at national tournament levels and were healthy at the time of strength measurement. The sample includes 25 people, who were randomly selected from among the population. Muscle strength in the muscles involved in the ankle, knee, and hip was measured at the beginning of the season before the start of the 2015 tournament using isotonic bodybuilding devices. Data were recorded on specified forms and tables. Then, their injuries were identified and recorded during 25 weeks of the tournament. Anthropometric characteristics of the subjects are listed in Table 1. To measure muscle strength, two subjects were used each time. Before starting measurements, subjects freely did their preheating exercises. Then, they were allowed to perform the related movements of the desired devices for 20-30 minutes before hitting their records (the highest approximate displacement weight) so that they could effort to break their records at the time of the main measurement stage.

To analyze the data, descriptive statistics such as mean and standard deviation, maximum and minimum values were used and to compare the mean difference of the survey subjects and investigate the relationship between muscle strength imbalance and muscle injuries, inferential statistics and independent t-test and Spearman correlation coefficient with a confidence level $(\mathrm{P}<.05)$ were used. In all the calculations steps, Excel 2012 and SPSS 19 software were used.

Table 1: Demographic characteristic of subjects

\begin{tabular}{ccccccccccccccc}
\hline & \multicolumn{4}{c}{ Age (year) } & \multicolumn{4}{c}{ Weight (kg) } & \multicolumn{4}{c}{ Height (cm) } & \multicolumn{3}{c}{ Dominant organ (person) } \\
\cline { 2 - 14 } & Min & Max & Mean & SD & Min & Max & Mean & SD & Min & Max & Mean & SD & Right & left \\
\cline { 2 - 14 } $\begin{array}{c}\text { Athletes } \\
(\mathrm{n}=25)\end{array}$ & 13 & 19 & 17.25 & 2.02 & 33 & 89 & 60.54 & 11.5 & 124 & 189 & 175.4 & 11.6 & 14 & 11 \\
\hline
\end{tabular}

\section{Findings}

According to Table 2 and Fig. 1, the highest mean value (94.60) and a dispersion of central index (20.11) is related to posteromedial muscle strength, while the lowest mean value (.17) and dispersion of central index (.05) is related to contrariwise time.

To investigate main indices related to psychological characteristics of elite and non-elite athletes using PCA method, the following steps were taken to obtain main parameters. Fig. 2 and Table 3 show the eigenvalues of variance corresponding to factors after varimax rotation. In the column of sum of the coefficients, factors of initial eigenvalues are presented in the form of sum of the explained variance for each of the factors. Explained variance is a percentage of total variance and cumulative percentage. Eigenvalue of each factor is a ratio of total variance of variables that is explained by that factor. Eigenvalue is significant as the sum of factorial squares of all variables in that factor. Eigenvalues, therefore, show the explanatory importance of factors associated with variable. Low levels of eigenvalue of a factor indicate that the factor has had a small role in explaining the variance.

Table 2: Mean of biomechanical characteristics of elite and non-elite athletes

\begin{tabular}{ccc}
\hline & Elite & Non-elite \\
\cline { 2 - 3 } Forward body & Mean & Mean \\
\cline { 2 - 3 } bending & 18.74 & 18.74 \\
Sit-up & 28.87 & 28.87 \\
Leg press & 87.33 & 87.33 \\
Sargent jump & 28.33 & 28.33 \\
Illinois & 22.89 & 22.89 \\
36 m & 8.59 & 8.59 \\
Ruler & 0.17 & 0.17 \\
Stork test (s) & 8.30 & 8.30 \\
Anterior star & 87.80 & 86.33 \\
Anteromedial star & 92.53 & 88.00 \\
Medial star & 91.07 & 90.47 \\
Posteromedial star & 94.60 & 94.47 \\
Posterior star & 91.47 & 93.13 \\
Posterolateral star & 88.07 & 87.80 \\
Posterior star & 78.53 & 82.67 \\
Posterolateral star & 81.47 & 84.20 \\
BASS (score) & 87.33 & 87.33 \\
\hline
\end{tabular}

Fig. 3 and Fig. 4 show angle to angle diagrams in two successful and unsuccessful landing in 75 and 
$105 \mathrm{~cm}$ jumping. These diagrams are an example of a subject.

Although diagrams followed the same pattern for other subjects, it was observed that the mean ankle to knee angle in successful landing was greater than unsuccessful landing and angle of successful landing, compared with an unsuccessful landing, remain at a higher level up to the end of the movement (Fig. 2). In both heights, the pattern of angle change of two joints is relatively similar to each other in both successful and unsuccessful landings (Fig. 3). It is just the mean joint angle that has caused unsuccessful landing to be done with an angle wider than successful landing (i.e. more extension).

Fig. 4 shows that in the beginning of the movement before the jumping time ( 0.9 seconds), changes in the location of pressure center in both successful and unsuccessful landings after high and short jumps is almost identical, but then (i.e. from the jump to landing stage) fluctuations of pressure center in unsuccessful landing are more than a successful landing, which indicates a lack of coordination and balance of subjects in unsuccessful landing. As can be seen in Fig. 5 and Fig. 6, the location of pressure center in two successful and unsuccessful landings on $\mathrm{y}$ axis is the same as $\mathrm{x}$ axis before the jumping stage, but then the fluctuations of pressure center in unsuccessful landing (especially short landing) are more than successful landing.

Table 3: Main indices related to the biomechanical characteristics of elite and non-elite athletes

\begin{tabular}{ccc}
\hline & Elite & Non-elite \\
\cline { 2 - 3 } Forward body bending & Mean & Mean \\
\cline { 2 - 3 } Sit-up & 0.86 & 0.777 \\
Leg press & 0.84 & 0.838 \\
Sargent jump & 0.92 & 0.89 \\
Illinois & 0.89 & 0.805 \\
36 m. & 0.93 & 0.833 \\
Ruler & 0.93 & 0.842 \\
Stork test (s) & 0.84 & 0.754 \\
Anterior star & 0.84 & 0.836 \\
Anteromedial star & 0.84 & 0.803 \\
Medial star & 0.91 & 0.853 \\
Posteromedial star & 0.87 & 0.8 \\
Posterior star & 0.92 & 0.828 \\
Posterolateral star & 0.86 & 0.782 \\
Posterior star & 0.84 & 0.784 \\
Posterolateral star & 0.92 & 0.916 \\
BASS (score) & 0.89 & 0.849 \\
\end{tabular}

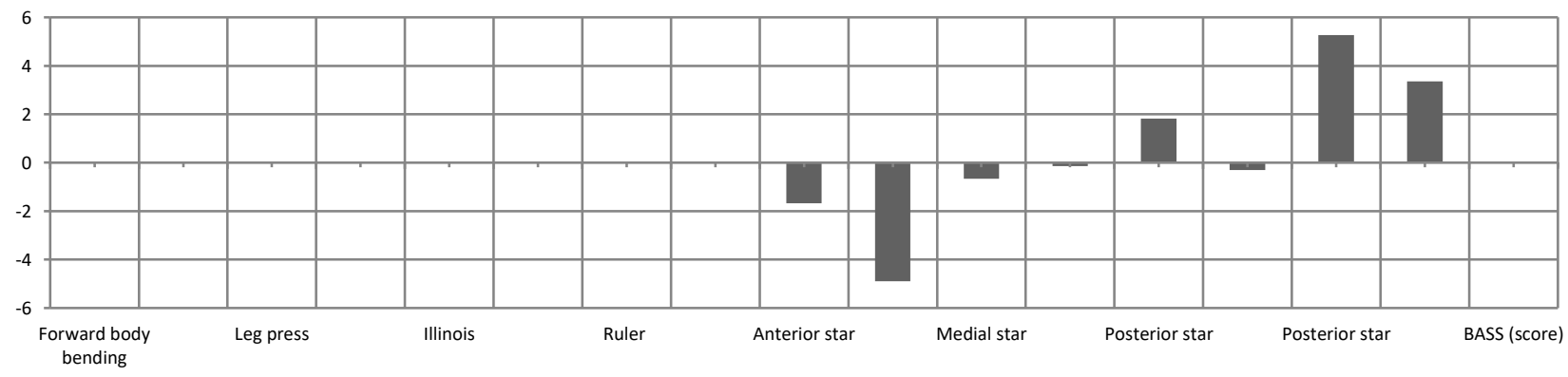

Fig. 1: Different of biomechanical characteristics of elite and non-elite athletes

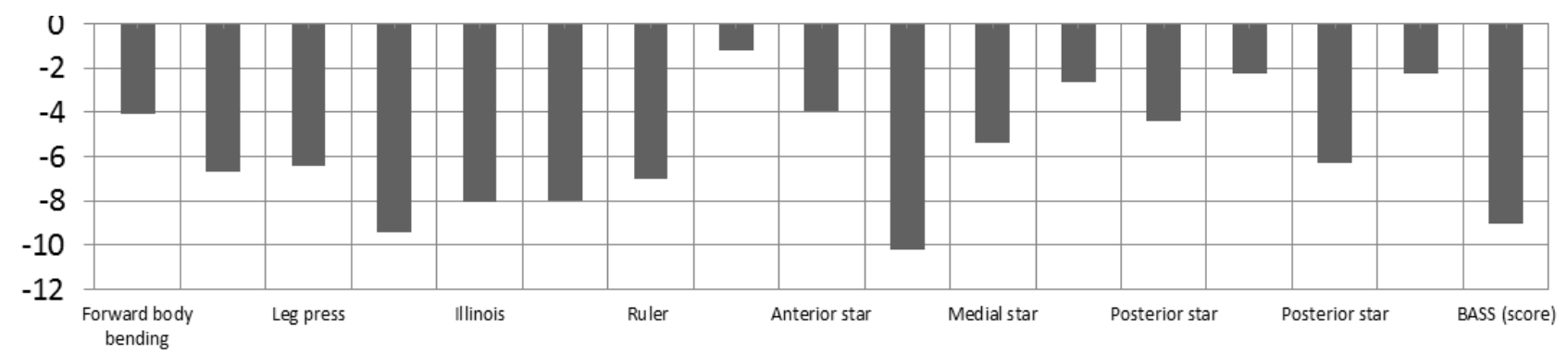

Fig. 2: Different of indices related to the biomechanical characteristics of elite and non-elite athletes

Based on inferential findings of the study in Table 4, the following relationships were observed:

- There is a significant relationship between dorsi flexor muscle strength imbalance in two dominant/non-dominant ankles and the prevalence of muscle injuries.

- There is a significant relationship between plantar flexor muscle strength imbalance in two dominant/non-dominant ankles and the prevalence of muscle injuries.

- There is a significant relationship between knee flexor muscle strength imbalance in two dominant/non-dominant feet and the prevalence of muscle injuries.
- There is a significant relationship between knee extensors muscle strength imbalance in two dominant/non-dominant feet and the prevalence of muscle injuries.

- There is a significant relationship between knee adductor muscle strength imbalance in two dominant/non-dominant feet and the prevalence of muscle injuries.

- There is a significant relationship between knee abductor muscle strength imbalance in two dominant/non-dominant feet and the prevalence of muscle injuries.

- The findings also showed that there is a significant relationship between dorsi flexor / plantar flexor muscle strength coordination ratio and the 
prevalence of muscle injuries in dominant / non-

migh/Suc
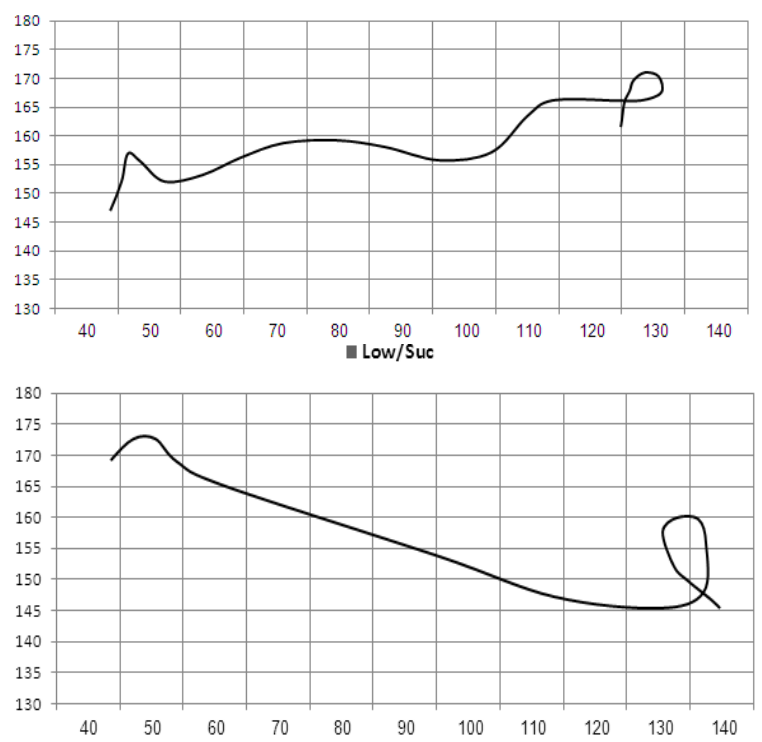

Fig. 3: Ankle and knee angle in landing after successful and unsuccessful fleche for two high and short jumps

- High/Suc
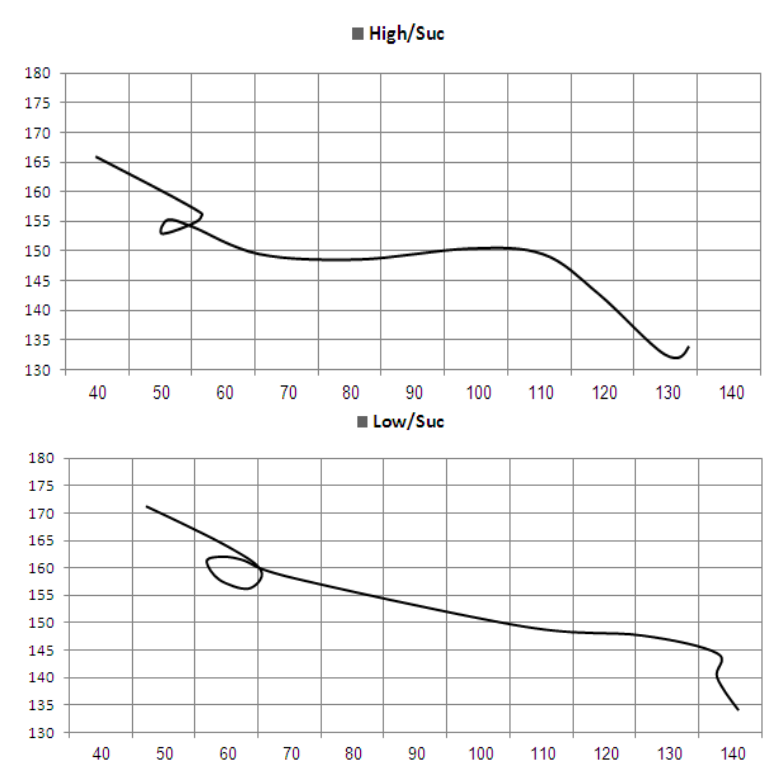

dominant feet.
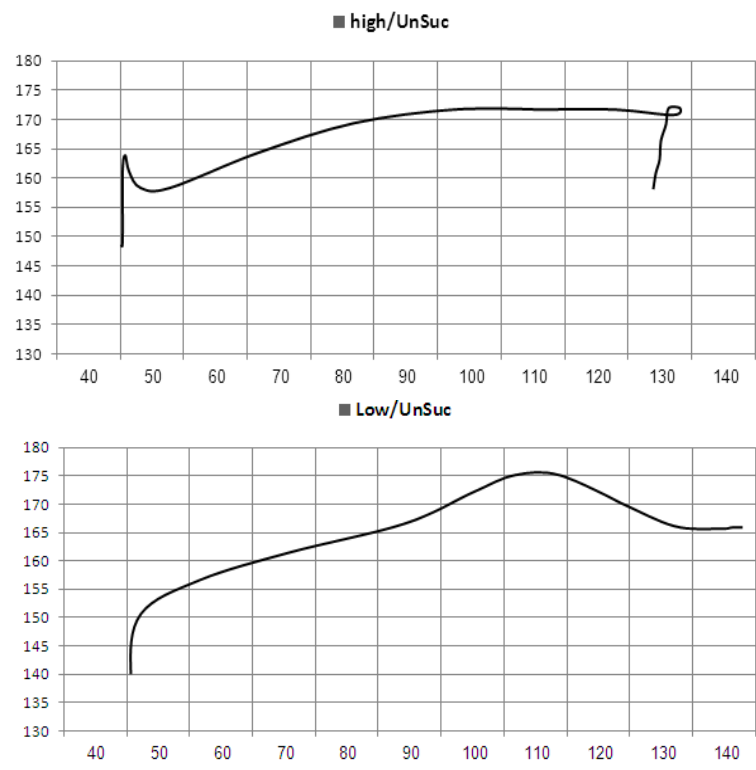
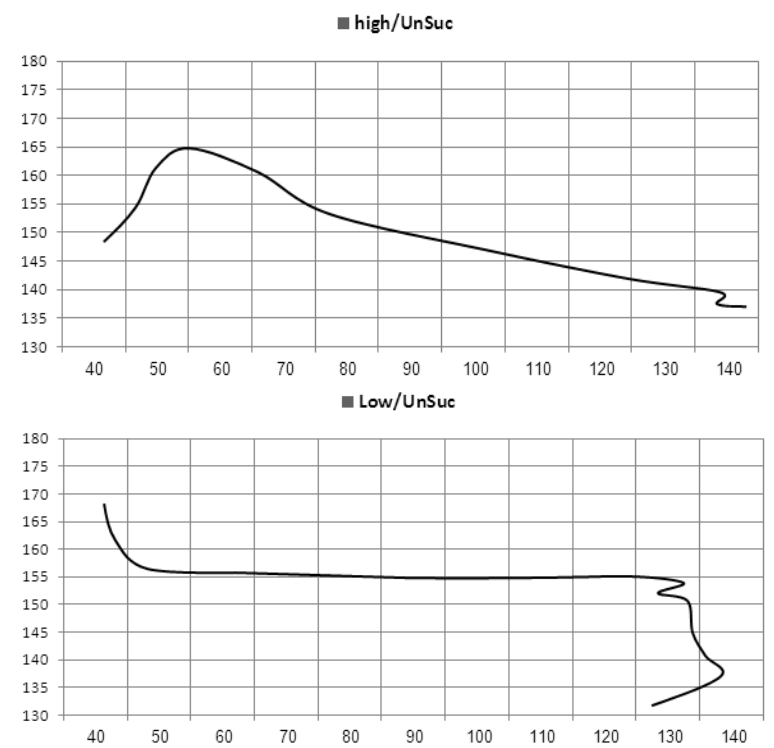

Fig. 4: Ankle and hip angle in landing after successful and unsuccessful fleche for two high and short jumps
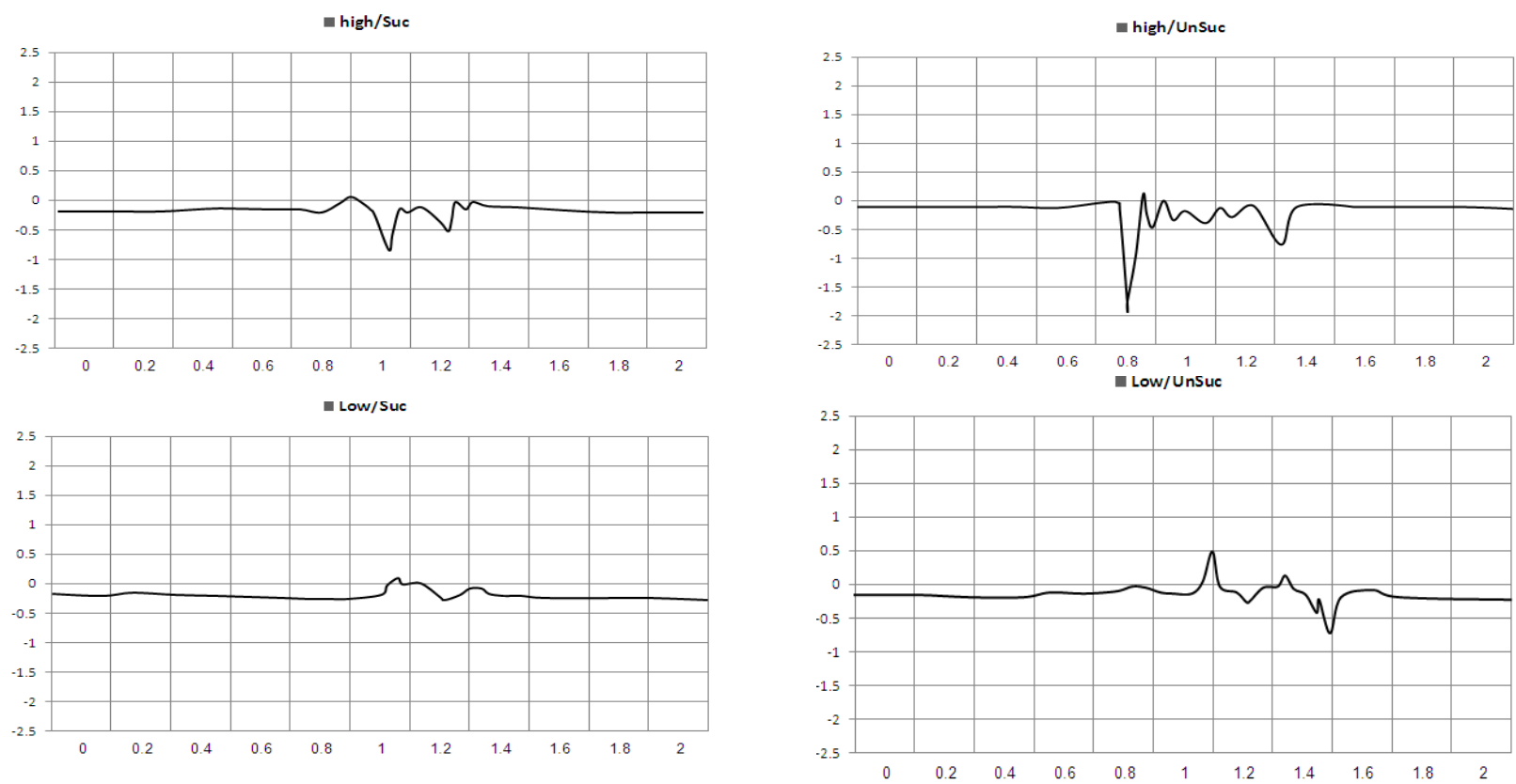

Fig. 5: Position of pressure center with respect to the origin of the successful and unsuccessful high and short landings 
- There is a significant relationship between dorsi flexor / plantar flexor muscle strength coordination ratio and the prevalence of muscle injuries in nondominant foot.

- There is a significant relationship between dorsi flexor / plantar flexor muscle strength coordination ratio and the prevalence of muscle injuries in dominant foot.

- There is a significant relationship between knee flexor / extensor muscle strength coordination ratio and the prevalence of muscle injuries in the knee of the non-dominant foot.

- There is a significant relationship between adductor / abductor muscle strength coordination ratio and the prevalence of muscle injuries in the thigh of the dominant foot.

- There is a significant relationship between thigh adductor / abductor muscle strength coordination ratio and the prevalence of muscle injuries in the thigh of the non-dominant foot.

- There is a significant relationship between flexibility coordination ratio and the prevalence of muscle injuries in ankle injuries at the time of landing.

- There is a significant relationship between muscular endurance coordination ratio and the prevalence of muscle injuries in ankle injuries at the time of landing.

- There is a significant relationship between muscle power coordination ratio and the prevalence of muscle injuries in ankle injuries at the time of landing.

- There is a significant relationship between agility coordination ratio and the prevalence of muscle injuries in ankle injuries at the time of landing.

- There is a significant relationship between stork test coordination ratio and the prevalence of muscle injuries in ankle injuries at the time of landing.

- There is a significant relationship between dynamic balance coordination ratio and the prevalence of muscle injuries in ankle injuries at the time of landing.

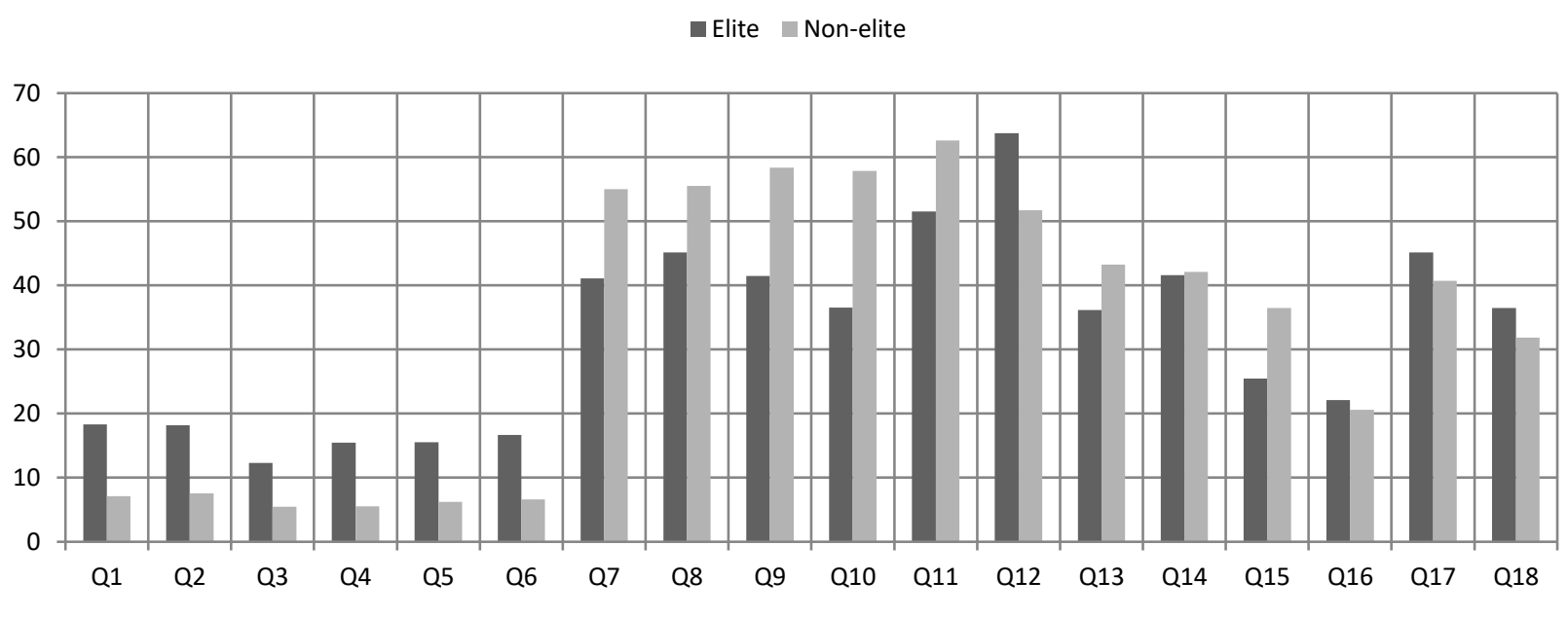

Fig. 6: Muscle strength

\section{Discussion and conclusion}

The present study aimed to evaluate biomechanical indices in elite and non-elite fencing athletes in the criteria of ankle injury when landing after performing the fleche technique. Flexibility, static balance, agility, anteromedial, medial, posteromedial, posterior, and posterolateral directions of star excursion balance test were used as the main biomechanical indices of elite fencing athletes and muscular endurance, muscle power, dynamic balance, medial, posterolateral, and posterior directions of star excursion balance test were the main biomechanical indices of non-elite fencing athletes.

The results showed that there was a significant difference between the main indices of biomechanical characteristics of muscular endurance (sit-up), muscular power (Sargent jump), agility (Illinois), static balance (stork) and dynamic balance and there was no difference between other main indices. The results are in line with the study of
Gürkan et al. (2012) in terms of balance and body fat percentage. Thorpe and Ebersole (2008) and McCurdy and Langford (2006) investigated the relationship between strength and balance among male athletes and reported that there isn't a relationship between strength and balance, which is consistent with the results of the present study. Gribble et al. (2004) studied the role of foot sole, height, leg length and ROM in performing star excursion balance test that was designed to evaluate the dynamic balance. The results showed that there is a significant positive relationship between leg lengths and performing star balance test and the longer the leg length, the distance achieved in each star test direction will be more.

Paillard et al. (2006) reported that gymnasts and fencers have better balance than non-elite athletes, which may be due to some of their exercises that increase the ability to use somatosensory and otolithic information and lead to enhancement of the ability of postural control. 
This result is consistent with the results of Barone et al. (2011) and Davlin (2004). Barone et al. (2011) compared the balance of fencers, basketball players, surfers and non-elite athletes and said that fencers have more balance when standing on the non-dominant foot as compared to non-elite athletes.

Table 4: Independent t-test to compare muscle strength imbalance in two injured and non-injured groups (in percentage)

\begin{tabular}{|c|c|c|c|c|}
\hline Statistics & Mean difference & DF & P-value & Results \\
\hline Q1: Coordination ratio of the two ankles' dorsi flexor muscle strength & 11.202 & 43 & 0.001 & Significant \\
\hline Q2: Coordination ratio of the two ankles' plantar flexor muscle strength & 10.507 & 43 & 0.0001 & Significant \\
\hline Q3: Coordination ratio of the two knees' flexor muscle strength & 6.555 & 43 & 0.002 & Significant \\
\hline Q4: Coordination ratio of the two knees' extensor muscle strength & 7.751 & 43 & 0.001 & Significant \\
\hline Q5: Coordination ratio of the two thighs' adductor muscle strength & 12.760 & 43 & 0.0001 & Significant \\
\hline Q6: Coordination ratio of the two thighs' abductor muscle strength & 8.444 & 43 & 0.0001 & Significant \\
\hline $\begin{array}{l}\text { Q7: Coordination ratio of muscle strength in agonist and antagonist muscles of } \\
\text { dominant ankle }\end{array}$ & 14.765 & 43 & 0.0002 & Significant \\
\hline $\begin{array}{l}\text { Q8: Coordination ratio of muscle strength in agonist and antagonist muscles of } \\
\text { dominant knee }\end{array}$ & 20.376 & 43 & 0.0001 & Significant \\
\hline $\begin{array}{l}\text { Q9: Coordination ratio of muscle strength in agonist and antagonist muscles of } \\
\text { dominant thigh }\end{array}$ & 16.700 & 43 & 0.0001 & Significant \\
\hline $\begin{array}{l}\text { Q10: Coordination ratio of muscle strength in agonist and antagonist muscles of } \\
\text { non-dominant ankle }\end{array}$ & 21.260 & 43 & 0.0001 & Significant \\
\hline $\begin{array}{l}\text { Q11: Coordination ratio of muscle strength in agonist and antagonist muscles of } \\
\text { non-dominant knee }\end{array}$ & 20.523 & 43 & 0.0001 & Significant \\
\hline $\begin{array}{l}\text { Q12: Coordination ratio of muscle strength in agonist and antagonist muscles of } \\
\text { non-dominant thigh }\end{array}$ & 16.860 & 43 & 0.0001 & Significant \\
\hline Q13: Coordination ratio of flexibility and injuries at the time of landing & 11.58 & 43 & 0.0001 & Significant \\
\hline Q14: Coordination ratio of muscular endurance and injuries at the time of landing & 12.58 & 43 & 0.0001 & Significant \\
\hline Q15: Coordination ratio of muscle power and injuries at the time of landing & 16.57 & 43 & 0.0001 & Significant \\
\hline Q16: Coordination ratio of agility and injuries at the time of landing & 24.65 & 43 & 0.0001 & Significant \\
\hline Q17: Coordination ratio of stork test and injuries at the time of landing & 11.98 & 43 & 0.0001 & Significant \\
\hline Q18: Coordination ratio of dynamic balance and injuries at the time of landing & 12.58 & 43 & 0.0001 & Significant \\
\hline
\end{tabular}

Davlin (2004) compared the dynamic balance of professional athletes in fencing, gymnastics, swimming and non-elite athletes and reported that gymnasts and fencers have more balance than nonelite athletes, which is in line with the results of the previously mentioned studies. Therefore, it seems that the difference between the main biomechanical parameters is due to the two groups' level of activity.

In general, the data obtained from this study are good criteria to evaluate and investigate the status of players and selection of young athletes in talent finding programs. Biomechanical indices of the population of fencers can be a measurement index to score and evaluate coaches of talent finding and other base centers across the country. National team coaches also can use the findings of this research to compare the status of the statistical population with other countries, determine the advantages and disadvantages, design special exercises, and choose the right team tactics. Youths are the back and future capital of the country's fencing and considering various aspects affecting guiding, nurturing and enjoying their efficiency at international level and global competitiveness is very important. Researchers are also recommended to conducted more studies on the main indicators related to skills in fencing and the relationship between these indicators and other main biomechanical indicators.

\section{References}

Abdollah S, Khosrow E, and Sajad A (2014). Comparison of anthropometric and functional characteristics of elite male Iranian fencers in three weapons. International Journal of Applied Sports Sciences, 26(1): 11-17.

Aquili A, Tancredi V, Triossi T, Sanctis D, Padua E, D'Arcangelo G, and Melchiorri G (2013). Performance analysis in saber. The
Journal of Strength and Conditioning Research, 27(3): 624630.

Aquilino GD, Longo AF, and Lentini NA (2012). Leg power in elite male fencers: A comparative study among the three competitive disciplines. In the Medicine and Science in Sports and Exercise, Lippincott Williams \& Wilkins, Philadelphia, USA, 44: 426-435.

Barone R, Macaluso F, Traina M, Leonardi V, Farina F, and Di Felice V (2011). Soccer players have a better standing balance in nondominant one-legged stance. Open Access Journal of Sports Medicine, 2: 1-6.

Benvenuti C, Minganti C, Condello G, Capranica L, and Tessitore A (2010). Agility assessment in female futsal and soccer players. Medicina (Kaunas), 46(6): 415-420.

Da Cunha RSP, Silva E, de Freitas WZ, and Fernandes Filho J (2008). Comparison of the level of flexibility between adult athletes of the Brazilian fencing team. Fitness and Performance Journal, 4(2): 74-84.

Davlin CD (2004). Dynamic balance in high level athletes. Perceptual and Motor Skills, 98(3_suppl): 1171-1176.

Elliott B (1992). A kinematic comparison of the male and female two-point and three-point jump shots in Fencing. Australian Journal of Science and Medicine in Sport, 24: 111-118.

Gribble PA, Hertel J, Denegar CR, and Buckley WE (2004). The effects of fatigue and chronic ankle instability on dynamic postural control. Journal of Athletic Training, 39(4): 321-329.

Gürkan AC, Sever O, Er FN, Suveren C, Kocak M, and Hazar M (2012). The comparison of balance and body fat percentage of elite futsal players and sedentary people. Niğde Üniversitesi Beden Eğitimi ve Spor Bilimleri Dergisi [Nigde University Journal of Physical Education And Sport Sciences], 6(3): 265270.

Knudson D (1993). Biomechanics of the Fencing jump shot—six key teaching points. Journal of Physical Education, Recreation and Dance, 64(2): 67-73.

McCurdy K and Langford G (2006). The relationship between maximum unilateral squat strength and balance in young adult men and women. Journal of Sports Science and Medicine, 5(2): 282-288. 
Oudejans RR, van de Langenberg RW and Hutter RV (2002). Aiming at a far target under different viewing conditions: Visual control in Fencing jump Hiting. Human Movement Science, 21(4): 457-480.

Özkol MZ, Turunç S, and Dopsaj M (2013). Water polo shots notational analysis according to player positions. International Journal of Performance Analysis in Sport, 13(3): 734-749.

Paillard T, Noe F, Riviere T, and Vincent M (2006). Postural performance and strategy in the unipedal stance of soccer players at different levels of competition. Journal of Athletic Training, 41(2): 172-176.

Rangarajan M (1999). Fencing the forest: conservation and ecological change in India's central provinces 1860-1914. Oxford University Press, Oxford, UK.

Rattray J (2006). A grounded theory study of midwives' decisionmaking: Use of continuous electronic foetal monitoring on low risk labouring women. Ph.D. Dissertation, Australian Catholic University, Sydney, Australia.

Russell WC (1996). Fence assembly with swivel bracket. U.S. Patent No. 5,547,169. U.S. Patent and Trademark Office, Washington, USA.

Thorpe JL and Ebersole KT (2008). Unilateral balance performance in female collegiate soccer athletes. The Journal of Strength and Conditioning Research, 22(5): 1429-1433.

Vila M, Abraldes JA, Alcaraz PE, Rodríguez N, and Ferragut C (2011). Tactical and Hiting variables that determine win or loss in top-Level in water polo. International Journal of Performance Analysis in Sport, 11(3): 486-498.

Vilas-Boas JP, Cruz J, Sousa F, Conceicao F, Fernandes R, and Carvalho J (2003). Biomechanical analysis of ventral swimming starts: comparison of the grab start with two trackstart techniques. In $9^{\text {th }}$ World Symposium on Biomechanics and Medicine in Swimming, University of Saint Etienne, Saint Etienne: 249-253. 